\title{
Comparing Three Attitude-Behavior Theories for Predicting Science Teachers' Intentions
}

\author{
Michaela Zint \\ School of Natural Resources and Environment, Dana Building, 430 E. University, \\ University of Michigan, Ann Arbor, Michigan 48109-1115
}

Received 28 December 2000; Accepted 2 May 2002

\begin{abstract}
Social psychologists' attitude-behavior theories can contribute to understanding science teachers' behaviors. Such understanding can, in turn, be used to improve professional development. This article describes leading attitude-behavior theories and summarizes results from past tests of these theories. A study predicting science teachers' intention to incorporate environmental risk education based on these theories is also reported. Data for that study were collected through a mail questionnaire $(n=1336$, $r_{\text {adjusted }}=80 \%$ ) and analyzed using confirmatory factor and multiple regression analysis. All determinants of intention to act in the Theory of Reasoned Action and Theory of Planned Behavior and some determinants in the Theory of Trying predicted science teachers' environmental risk education intentions. Given the consistency of results across studies, the Theory of Planned Behavior augmented with past behavior is concluded to provide the best attitude-behavior model for predicting science teachers' intention to act. Thus, science teachers' attitude toward the behavior, perceived behavioral control, and subjective norm need to be enhanced to modify their behavior. Based on the Theory of Trying, improving their attitude toward the process and toward success, and expectations of success may also result in changes. Future research should focus on identifying determinants that can further enhance the ability of these theories to predict and explain science teachers' behaviors. (c) 2002 Wiley Periodicals, Inc. J Res Sci Teach 39: 819-844, 2002
\end{abstract}

Science teachers influence what students are taught and how they are taught, and thus are key to student achievement (Tobin, 1998). Current education reform efforts recognize how critical science teachers are to meeting content and pedagogy goals (Bybee \& Ben-Zvi, 1998). Moreover, it is acknowledged that the significant modifications in practice that are needed will be difficult to attain because science teachers, like the rest of us, are likely to be resistant to change (Lumpe, Haney, \& Czerniak, 2000).

\footnotetext{
Contract grant sponsor: Office of Sea Grant, National Oceanic and Atmospheric Administration

Contract grant number: 1N89AA-D-SG083

Contract grant sponsor: State of Michigan

Correspondence to: M. Zint; E-mail: zintmich@umich.edu

DOI 10.1002/tea.10047

Published online in Wiley InterScience (www.interscience.wiley.com).
} 
So how can science education reform and other needed changes in science teachers' practices be fostered? As suggested by science education investigators as early as Koballa $(1986,1989)$ and Crawley (1988, 1990) and as recently as Haney, Czerniak, and Lumpe (1996) and Lumpe, Haney, and Czerniak (1998a, 1998b) such changes can be achieved by learning why teachers behave the way they do, and then designing professional development programs in ways that target these determinants (Haney \& Lumpe, 1995).

For this purpose, and similar to others interested in understanding human behavior, these and other science education investigators have turned to social psychology's attitude-behavior theories, guided primarily by the theory of reasoned action (Fishbein \& Ajzen, 1975; Ajzen \& Fishbein, 1980; Fishbein, 1980) and expanded by theories that seek to overcome its boundaries such as the theory of planned behavior (Ajzen, 1985, 1991) and trying (Bagozzi \& Warshaw, 1990). According to these theories, behavior change is brought about by modifying individuals' intention to act. Changes in intention to act are brought about by influencing the immediate determinants of intention to act, which are in turn brought about by influencing underlying beliefs (Figure 1).

The importance of targeting science educators' beliefs to change their teaching behaviors has been recognized in many science education contexts (Tobin, Tippins, \& Gallard, 1994). The attitude-behavior theories reviewed here indicate how changes in science teachers' beliefs can lead to modifications in science teachers' behaviors.

\section{Purpose}

Many theories and models seek to understand how and why individuals including science teachers change (Richardson \& Placier, 2001). Among these, the attitude-behavior theories examined here have been, and continue to be, particularly popular because of their relative ability to predict behavior, simplicity, and ease of operationalization (Sutton, 1998).

To date, science education investigators have referenced select previous work but have not provided a summary of findings of tests of these theories. Given the large number of studies conducted with science and other teachers as well as reviews of studies conducted with other populations available at this time, it seemed appropriate to provide such a summary. The purpose of this effort was to provide a comprehensive assessment for those seeking to advance research on understanding science teachers' behaviors and to improve professional development programs based on these theories.

As suggested by the introduction, the article focuses on the theories of reasoned action (TRA), planned behavior (TPB), and trying (TT) in terms of their ability to predict science teachers' intention to act and thus, according to the three theories, science teachers' behavior. The article focuses on intention to act and its immediate determinants (Figure 1).

Specifically, the article's assessment of the three theories' ability to predict science teachers' intention to act is based on a summary of past research including 21 data sets from studies conducted mostly with science teachers or seeking to predict the teaching of science education topics and methods (Table 1). This assessment is supplemented by the reporting of a study that, unlike the majority of past research involving teachers, is based on a large, representative sample, involved a field-based investigation, and consisted of a simultaneous test of the three theories under investigation.

The study reported here was conducted in the context of environmental risk education because improvements in youths' human health, environmental health, and ecological risk decisions are needed (Wilson, 1990; Gregory, 1991; Briscoe, 1992; Riechard, 1993; Independent 


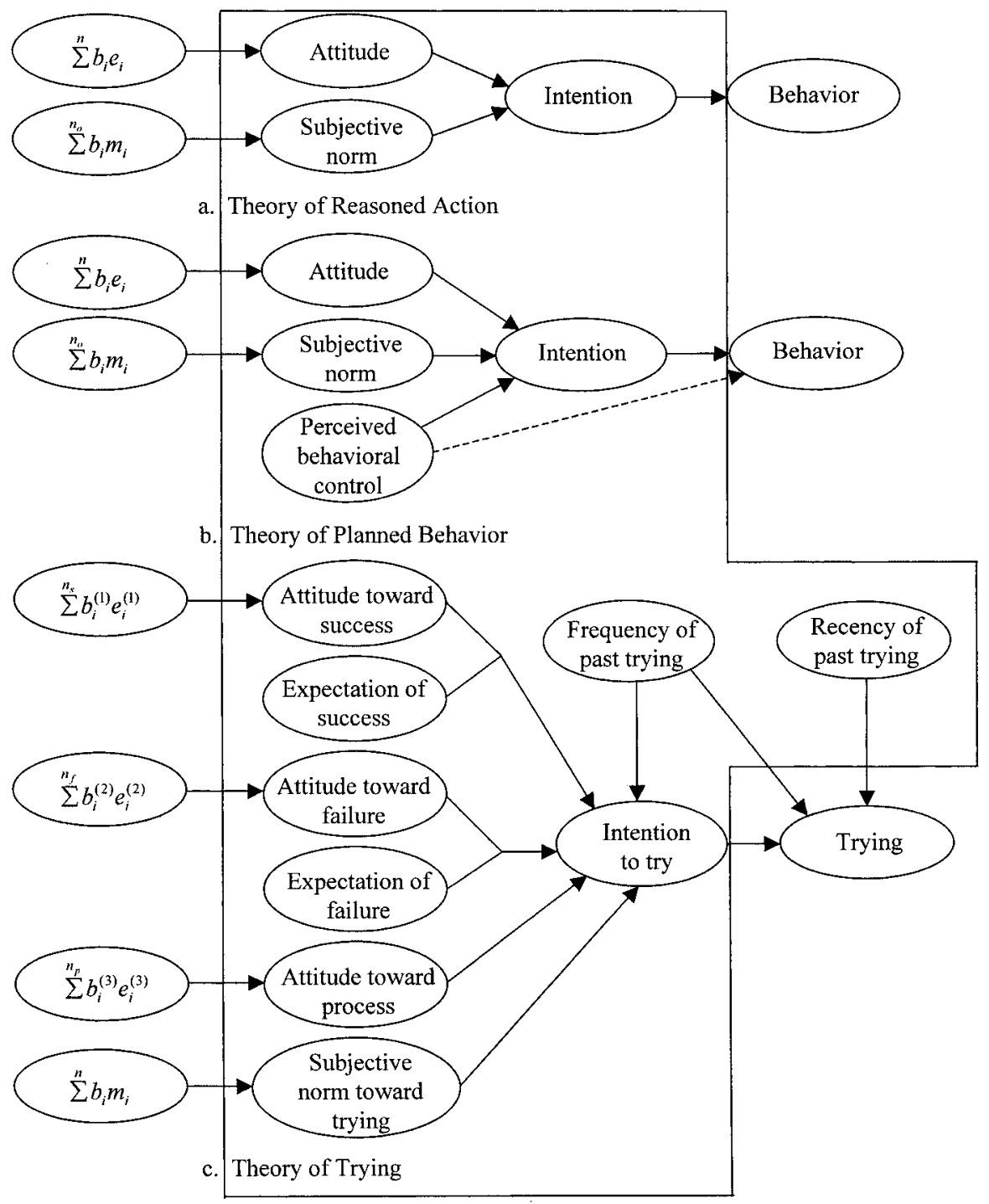

Note: $\mathrm{n}=$ the number of beliefs, evaluations or motivations associated with construct, $\mathrm{b}_{\mathrm{i}}=$ the belief that behavior leads to outcome (for attitude measures); or the belief that individuals or groups think the individual should or should not perform the behavior (for subjective norm measure), $\mathrm{e}_{\mathrm{i}}=$ the evaluation of outcomes, and $\mathrm{m}_{\mathrm{j}}=$ the motivation to comply with referents. Determinants in $\square$ are the focus of this paper.

Figure 1. Theories of Reasoned Action (TRA), Planned Behavior (TPB), and Trying (TT) (Bagozzi, 1992).

Commission on Environmental Education, 1997; Zint, 2001) and national science education standards [American Association for the Advancement of Science (AAAS), 1993; National Research Council (NRC), 1996] and programs (College Board, 2000) identify teaching about these risks as important to achieving scientific literacy. Descriptive results of science teachers' environmental risk education needs are reported in Zint and Peyton (2001). 


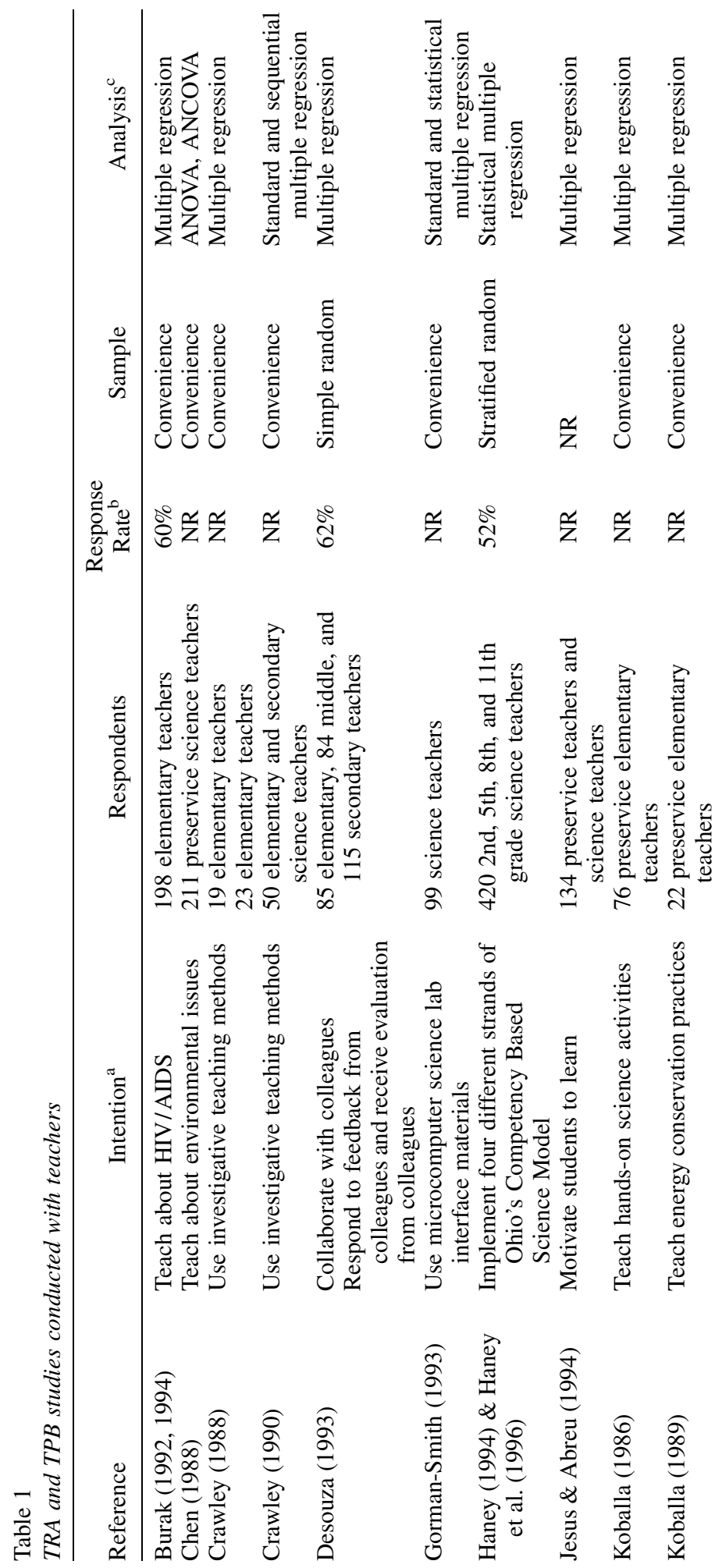




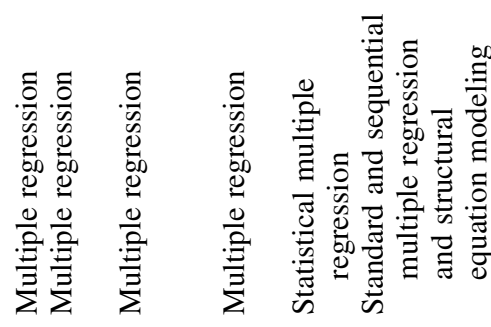

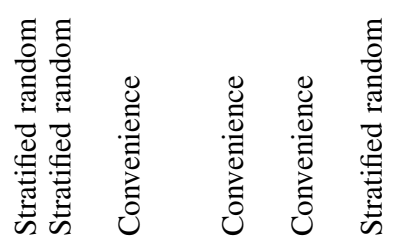

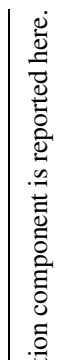

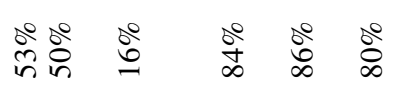

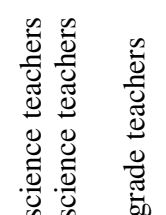

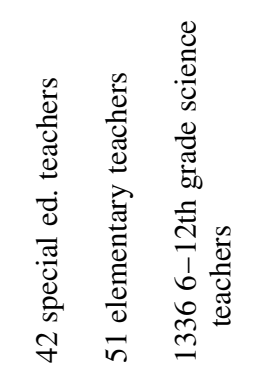

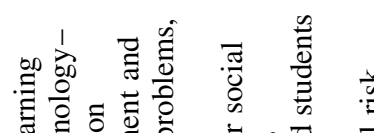

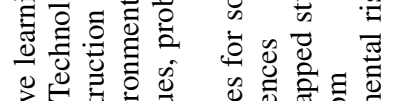

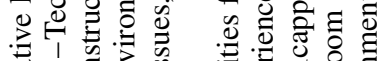

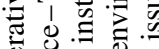

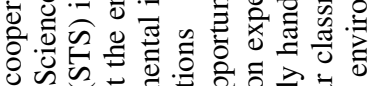

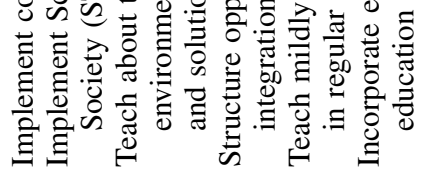

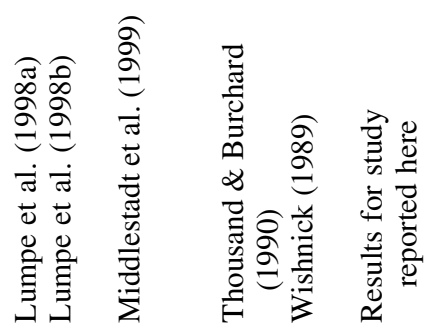

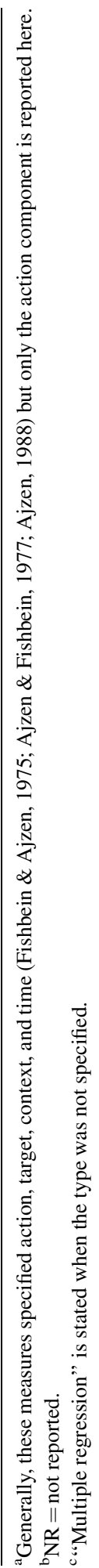




\section{Theoretical Base and Prior Research}

\section{Theory of Reasoned Action (TRA)}

The TRA (Fishbein \& Ajzen, 1975; Ajzen \& Fishbein, 1980; Fishbein, 1980) suggests that a volitional or voluntary behavior (B) can be predicted directly by individuals' intention to perform the behavior (I) [i.e., "people's expectancies about their own behavior in a given setting" (Fishbein \& Ajzen, 1975, p. 288)]. This intention to act (I) is a function of two determinants, "one personal in nature and the other reflecting social influence" (Ajzen \& Fishbein, 1980, p. 6). The attitudinal component is termed attitude toward the behavior or act $\left(\mathrm{A}_{\mathrm{act}}\right)$ (i.e., an evaluation of the behavior as favorable or unfavorable) and the normative component is termed subjective norm (SN) (i.e., the perceived social pressure to perform or not to perform the behavior). The relative importance of these two determinants in predicting intention to act is expected to vary with the type of behavior, situation, and based on individual differences (Ajzen \& Fishbein, 1973). Variables other than attitude toward the behavior and subjective norm are assumed to influence intention to act and behavior indirectly through these two determinants.

In the context of this article, the TRA suggests that science teachers with a favorable disposition toward incorporating environmental risk education $\left(\mathrm{A}_{\mathrm{act}}\right)$ and science teachers who perceive social pressure (e.g., from principal, parents, colleagues) to incorporate environmental risk education (SN) are likely to form an intention to incorporate environmental risk education (I).

Tests of the TRA conducted with populations other than teachers support the theory's ability to predict intention to act and behavior. For example, based on a review of 21 data sets, Ajzen and Fishbein (1973) reported a mean multiple correlation $(R)$ of .78 (range .38-.93) for the prediction of intention to act from attitude toward the behavior and subjective norm, and a mean correlation $(r)$ of .65 (range .21-.97) between intention to act and behavior. Sheppard, Hartwick, and Warshaw (1988) conducted a meta-analysis of 87 studies and reported a mean multiple correlation $(R)$ of .66 (range .23-.94) for the prediction of intention to act from attitude toward the behavior and subjective norm, and a mean correlation $(r)$ of .53 (range $.10-.96)$ between intention to act and behavior. Van den Putte [(1991) as cited in Eagly \& Chaiken, 1993] conducted a meta-analysis of 150 data sets and reported a mean multiple correlation $(R)$ of .68 for predicting intention to act from attitude toward the behavior and subjective norm, and a mean correlation $(r)$ of .62 between intention to act and behavior.

Two of these reviews also provided information about the relative importance of attitude toward the behavior and subjective norm in predicting intention to act. Attitude toward the behavior significantly predicted intention to act in $86 \%(n=18)$ and subjective norm in $67 \%$ $(n=14)$ of the data sets reviewed by Ajzen and Fishbein (1973). When these determinants were significant predictors of intention to act, they were of similar relative importance (attitude toward the behavior $\bar{x} r=.67$, range $.37-.91 ; \bar{x} \beta=.54$, range $.29-.76$; subjective norm $\bar{x} r=.68$, range $.41-.84 ; \bar{x} \beta=.51$, range $.23-.95)$. In slight contrast, the meta-analysis of 150 data sets by Van den Putte [(1991) as cited by Eagly \& Chaiken, 1993] suggested a stronger relation between attitude toward the behavior and intention to act $(\bar{x} r=.60)$ than between subjective norm and intention to act $(\bar{x} r=.42)$.

Results of studies conducted with teachers (Table 2) also support the TRA. The mean multiple correlation $(R)$ for fourteen teacher data sets was .54 (range .10-.85) and was thus slightly lower but in the range of results reported in reviews of studies conducted with other populations [Ajzen \& Fishbein, 1973; Sheppard et al., 1988; Van den Putte, 1991 (as cited in Eagly \& Chaiken, 1993)]. Attitude toward the behavior significantly predicted intention to act in $69 \%(n=9)$ and subjective norm in $85 \%(n=11)$ of the 14 teacher data sets. When these determinants were significant 
COMPARING THREE ATTITUDE-BEHAVIOR THEORIES

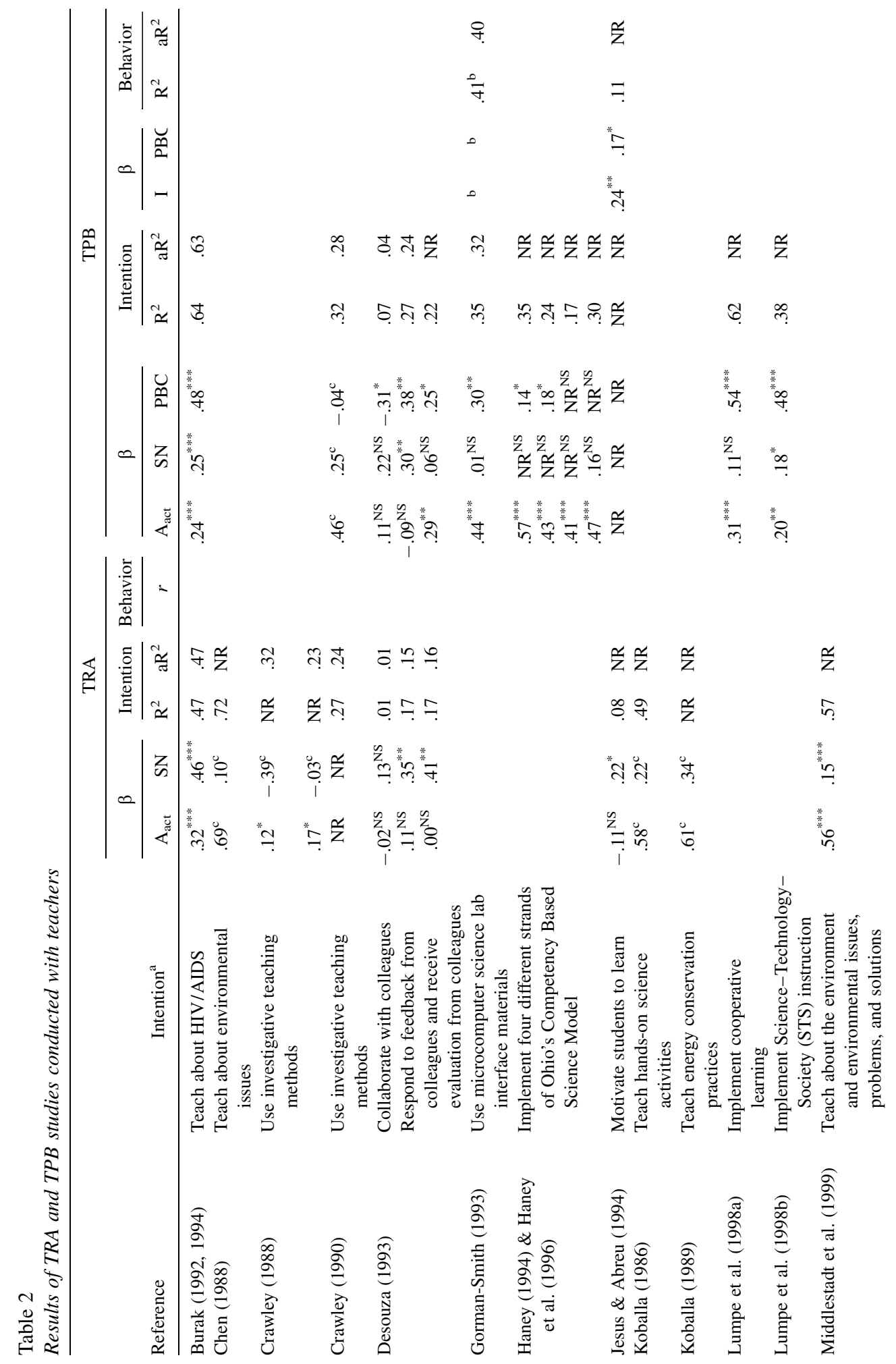




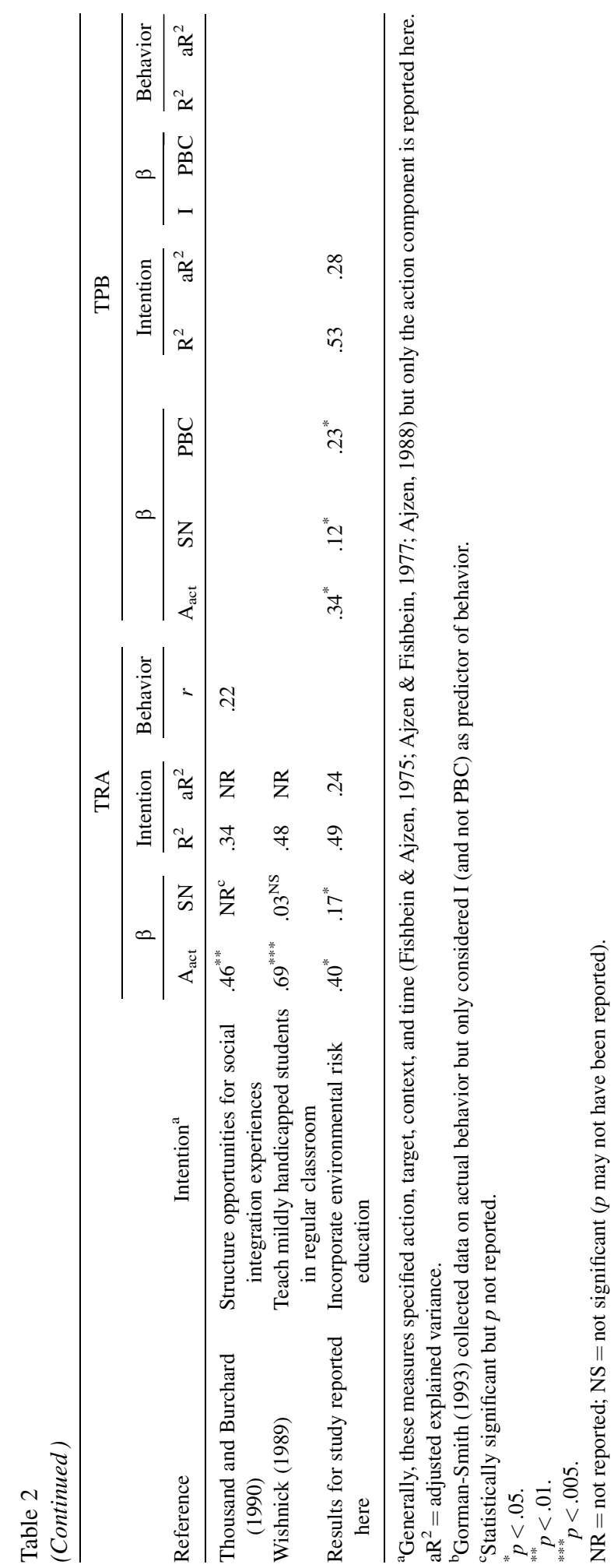


predictors of intention to act in these TRA studies conducted with teachers, the relative importance of attitude toward the behavior was greater $(\bar{x} \beta=.47$, range $.12-.69)$ than that of subjective norm $(\bar{x} \beta=.18$, range $-.39-.46)$, as in the majority of TRA studies conducted with other populations [Van den Putte, 1991 (as cited by Eagly \& Chaiken, 1993)].

Only one TRA study conducted with teachers reported actual behavior data (Thousand \& Burchard, 1990). That study's correlation between intention to act and behavior was small $(r=.22)$ in light of the mean $(\bar{x}$ range $.53-.65)$ correlations reported in reviews of studies conducted with other populations [Ajzen \& Fishbein, 1973; Sheppard et al., 1988; Van den Putte, 1991 (as cited by Eagly \& Chaiken, 1993)] and may have occurred because of an 8-week delay between the measurement of intention to act and behavior (Ajzen, 1996).

\section{Theory of Planned Behavior (TPB)}

Ajzen $(1985,1988,1991)$ developed the TPB because the TRA is limited to predicting behaviors over which individuals have volitional control (Ajzen \& Fishbein, 1980) (i.e., behaviors that do not require special skills, resources, or support and hence can be performed at will) and Ajzen $(1985,1988,1991)$ recognized that the extent to which some intentions to act can be carried out depends partially on the levels of control individuals have over behaviors. Consistent with Bandura's (1977, 1982) work on self-efficacy [i.e., "the conviction that one can successfully execute (a) behavior" (Bandura, 1977, p. 193)], the TPB therefore adds perceived behavioral control (PBC) (i.e., the belief as to how easy or difficult performance of the behavior is likely to be) as a predictor of intention to act and behavior. Perceived behavioral control is assumed to reflect the opportunities and resources needed to engage in behavior. Thus, the path between perceived behavioral control and intention to act reflects individuals' perceived control over the behavior, whereas the path between perceived behavioral control and behavior reflects actual control over the behavior (Ajzen, 1985). As with the TRA, the relative importance of the three determinants in predicting intention to act is expected to vary with the type of behavior and situation, and is based on individual differences (Ajzen, 1985, 1988, 1991).

In the context of this article, the TPB suggests that science teachers will intend to incorporate environmental risk education (I) when they have a favorable disposition toward doing so $\left(\mathrm{A}_{\mathrm{act}}\right)$, when they perceive social pressure to do so $(\mathrm{SN})$, and when they are confident in their ability to incorporate environmental risk education (PBC).

The TPB was expected to predict science teachers' intention to incorporate environmental risk education better than the TRA because science teachers are likely to have limited volitional control over incorporating environmental risk education. This hypothesis was based on the many constraints that science teachers identified to incorporating environmental risk education (Zint \& Peyton, 2001).

Tests of the TPB conducted with populations other than teachers support its ability to predict intention to act and behavior. For example, a review of 19 data sets (Ajzen, 1991) provided a mean multiple correlation $(R)$ of .70 (range .43-.94) for the prediction of intention to act from attitude toward the behavior, subjective norm, and perceived behavioral control, and a mean multiple correlation $(R)$ of .50 (range $.23-.84$ ) for the prediction of behavior from intention to act and perceived behavioral control. The same review (Ajzen, 1991) also indicated that perceived behavioral control was a significant predictor of intention to act in all 19 data sets and attitude toward the behavior in all but $1(5 \%)$ of 19 data sets. In some contrast, subjective norm was only a significant predictor of intention to act for $53 \%(n=10)$ of 19 data sets. When these determinants were significant, attitude toward the behavior was the most important predictor of intention to act $(\bar{x} \beta=.39$, range $.10-.79)$, closely followed by perceived behavioral control $(\bar{x} \beta=.39$, range 
$.07-.84)$, and then subjective norm $(\bar{x} \beta=.17$, range $-.24-.35)$. A recent meta-analysis of 185 tests of the TPB (Armitage \& Conner, 2001) obtained similar results for the prediction of intention to act from attitude toward the behavior, subjective norm, and perceived behavioral control $(\bar{x} R=.63)$ and for the prediction of behavior from intention to act and perceived behavioral control $(\bar{x} R=.52)$. The analysis also indicated that the attitude toward the behavior was most strongly correlated with intention to act $(\bar{x} r=.49)$, closely followed by perceived behavioral control $(\bar{x} r=.43)$, and then subjective norm $(\bar{x} r=.34)$.

Results of studies conducted with teachers (Table 2) also support the TPB. The mean multiple correlation $(R)$ for 13 teacher data sets was .56 (range .26-.80) for the prediction of intention to act from attitude toward the behavior, subjective norm, and perceived behavioral control, and thus somewhat lower than that in the review of studies conducted with other populations (Ajzen, 1991; Armitage \& Conner, 2001). Attitude toward the behavior and perceived behavioral control were significant predictors of intention to act in all but $2(17 \%)$ of 12 teacher data sets. In some contrast, subjective norm was only a significant predictor of intention to act in $33 \%(n=4)$ of 12 teacher data sets. When these determinants were significant predictors of intention to act, attitude toward the behavior was the most important predictor $(\bar{x} \beta=.38$, range $.20-.57)$, followed by both subjective norm $(\bar{x} \beta=.25$, range $.28-.30)$ and perceived behavioral control $(\bar{x} \beta=.24$, range $-.31-.54)$. Thus, although subjective norm was not as frequent a significant predictor of teachers' intention to act (Table 2) as of other populations' intention to act (Ajzen, 1991), when it was significant, subjective norm was of some greater importance in TPB studies conducted with teachers (Table 2) than in TPB studies conducted with other populations (Ajzen, 1991; Armitage \& Conner, 2001).

Only two TPB studies conducted with teachers reported actual behavior data (Gorman-Smith, 1993; Jesus \& Abreu, 1994). However, only Jesus and Abreu (1994) predicted behavior based on intention to act and perceived behavioral control. That study's multiple correlation was small $(R=.33)$ in light of the mean $(\bar{x} R=.50)$ and range $(.23-.84)$ reported in a review of studies conducted with other populations (Ajzen, 1991), possibly because of the outcome orientation of the target behavior (Ajzen \& Fishbein, 1980). The other TPB study (Gorman-Smith, 1993) only reported the correlation between intention to act and behavior as opposed to the multiple correlation including perceived behavioral control. That correlation $(r=.64)$ was much higher than the correlation $(r=.22)$ reported by Thousand and Burchard (1990), and thus is more consistent with the correlations $(\bar{x} r=.53-.65$, range $.10-.97)$ reported in reviews of TRA studies conducted with other populations [Ajzen \& Fishbein, 1973; Sheppard et al., 1988; Van den Putte, 1991 (as cited by Eagly \& Chaiken, 1993)].

Studies also support that the TPB better predicts intention to act and behavior than the TRA when individuals have limited volitional control over the behavior. For example, one study conducted with populations other than teachers found that the explained variance increased $10 \%$ in intention to act and $14 \%$ in behavior across 10 various behaviors as a result of adding perceived behavioral control to the TRA (Madden, Scholder, \& Ajzen, 1992). Another study consisting of a meta-analysis of 185 tests of the TPB found that perceived behavioral control added a mean of 5\% to the prediction of intention to act (Armitage \& Conner, 2001). In all five cases of TRA and TPB comparisons conducted with teachers (Table 2 ), the TPB was also better able to predict intention to act than the TRA, and by a similar amount $\left(\bar{x}\right.$ adjusted $R^{2}$ difference $=8 \%$, range $\left.3-16 \%\right)$.

\section{Theory of Trying (TT)}

The TT (Bagozzi \& Warshaw, 1990) expands on the originally proposed TPB (Ajzen, 1985) and attempts to explain the process of striving (i.e., trying) to perform a behavior or to achieve a 
goal [i.e., a behavior perceived as problematic to its outcome or success (Bagozzi \& Warshaw, 1990)]. The TT differs from the TRA and TPB in three main ways: (a) it measures three attitudes [attitude toward success $\left(A_{s}\right)$, failure $\left(A_{f}\right)$, and the process $\left(A_{p}\right)$ ] rather than a single unidimensional attitude and incorporates two self-efficacy judgments as expectations of success $\left(E_{s}\right)$ and failure $\left(E_{f}\right)$ to define aspects of goal pursuit; (b) it suggests that $A_{s}$ and $A_{f}$ will influence intention to act (I) to the extent that $\mathrm{E}_{\mathrm{s}}$ is high and $\mathrm{E}_{\mathrm{f}}$ is low [based on work of Lewin, Dembo, Festinger, and Sears (1944) on goals]; and (c) it proposes that past behavior (PB) defined both in terms of frequency and recency has a direct effect on intention to act and behavior (i.e., it is not channeled indirectly through the determinants of intention to act and behavior). Past behavior (PB) is argued to serve a theoretical purpose [i.e., reflecting habit, "one's customary ways of behaving" (Ouellette \& Wood, 1998, p. 54) or experience, and hence providing information input] (Triandis, 1977, 1980; Bentler \& Speckart, 1979) and a methodologic purpose [i.e., if the model contains all determinants, past behavior should not improve the prediction of future behavior) (Ajzen, 1991)].

In the context of this article, the TT suggests that science teachers' attitude toward succeeding $\left(A_{s}\right)$ and attitude toward failing $\left(A_{f}\right)$ to incorporate environmental risk education will lead to intentions to incorporate environmental risk education (I) to the extent that these teachers' expectations (i.e., subjective probabilities) of success are high $\left(\mathrm{E}_{\mathrm{s}}\right)$ and expectations of failure $\left(\mathrm{E}_{\mathrm{f}}\right)$ are low, respectively. Science teachers' intention to incorporate environmental risk education (I) are also expected to be influenced by these teachers' attitude toward the consequences that will occur as they are striving to incorporate environmental risk education $\left(\mathrm{A}_{\mathrm{p}}\right)$ regardless of the outcome and by how often and how recently they have incorporated environmental risk education in the past (PB). Given the goal-oriented nature (Bagozzi, 1992) of incorporating environmental risk education, it was hypothesized that the TT would better predict science teachers' intentions to incorporate environmental risk education than the TRA and TPB.

Tests of the TT support its ability to predict intention to act and behavior (Bagozzi \& Warshaw, 1990; Bagozzi et al., 1992; Bagozzi \& Kimmel, 1995) with a mean multiple correlation (R) of .68 (range .33-.78) for the prediction of intention to act and a mean multiple correlation (R) of .70 (range .66-.78) for the prediction of behavior. Results for the determinants of intention to act and behavior were mixed in past studies (Bagozzi \& Warshaw, 1990; Bagozzi, Davis, \& Warshaw, 1992; Bagozzi \& Kimmel, 1995) but provided some support for the multidimensional conceptualization of attitude, the proposed main and interaction effects, and the relations among past behavior, intention to act, and behavior.

Only one study has compared the TRA and TPB, the TRA and TPB augmented with past behavior, and the TT (Bagozzi \& Kimmel, 1995). Results indicated that the TPB was better able to predict intention to act than the TRA (by 5\% for two behaviors) and the TT (by 7\% and $4 \%$ for two behaviors). When the TRA and TPB were augmented with past behavior, the two theories increased in their ability to predict intention to act (under the TRA by $8 \%$ and $11 \%$ for two behaviors; under the TPB by $3 \%$ and $6 \%$ for two behaviors). No studies of teachers' behavioral intentions have applied the TT.

\section{Methods}

\section{Questionnaire and Measures}

Data for the comparison of the TRA, TPB, and TT in predicting science teachers' intention to incorporate environmental risk education were collected through a mail questionnaire.

The wording of the measures used in the questionnaire was based on personal interviews and focus groups with over 60 science teachers. These conversations revealed that science teachers 
described "risk" (i.e., the probability that harm will occur) consistent with how risk is defined (Kaplan, 1997) and that they thought of teaching about environmental risk decisions in ways consistent with national science education standards (AAAS, 1993; NRC, 1996). Nonetheless, definitions of risk and of teaching about environmental risk decisions were also provided preceeding relevant measures in the instrument.

In addition to selecting the wording of the study's measures based on language used by science teachers, the wording of each measure was determined by the three theories' authors' specifications: i.e., Ajzen and Fishbein (1980) for the TRA, Ajzen and Madden (1986) for the TPB, and Bagozzi and Kimmel (1995) for the TT constructs. All measures were also compatible in terms of action, target, context, and time to maximize prediction according to the principle of correspondence (Fishbein \& Ajzen, 1975; Ajzen \& Fishbein, 1977; Ajzen, 1988). Finally, each measure had seven response options labeled extremely, quite, slightly, neither, slightly, quite, and extremely.

A pilot-test with over 100 science teachers did not reveal concerns over the wording of the instrument's measures and the final mailed questionnaire included the three theories' 10 constructs measured with the following 14 items.

Intention to Act (I). Intention to act was measured with: "It is (likely/unlikely) that I will teach my students about decisions involving environmental risk during this school year." One likely/unlikely item followed.

Attitude Toward the Behavior $\left(A_{a c t}\right)$. This attitude was measured with: "Teaching my students about decisions involving environmental risk during this school year would make me feel..." Two items followed: content/discontent and satisfied/unsatisfied.

Attitude Toward Success $\left(A_{s}\right)$ and Attitude Toward Failure $\left(A_{f}\right)$. Attitude toward success was measured by: "Assuming I tried and that I was successful in improving my students' decisions involving environmental risk during this school year, I would feel ..." Attitude toward failure was measured by: "Assuming that I tried but failed in improving my students' decisions involving environmental risk during this school year, I would feel ..." Both were followed by the same two items as attitude toward the behavior.

Expectations of Success $\left(E_{s}\right)$ and Expectation of Failure $\left(E_{f}\right)$. To measure these two constructs, respondents were asked to respond to: "Assuming I tried to teach my students about decisions involving environmental risk during this school year, it is (likely/unlikely) that I would actually be successful/fail in improving their decisions."

Attitude Toward the Process $\left(A_{p}\right)$. This attitude was measured by: "Considering all the things I would have to do to teach my students about decisions involving environmental risk during this school year, my attitude toward doing these things can best be described as making me feel..." Two items, enthusiastic/reluctant and unconcerned/concerned, followed.

Subjective Norm $(S N)$. Subjective norm was measured by asking teachers to respond to: "Most people who are important to me professionally would (approve/disapprove) of my teaching my students about decisions involving environmental risk during this school year." 
Perceived Behavioral Control (PBC). This construct was measured with: "For me, teaching my students about decisions involving environmental risk during this school year would be ..." One easy/difficult item followed.

Past Behavior (PB). Past behavior was determined by asking teachers to indicate to what extent they agreed or disagreed with the following statement: "I have taught my students about decisions involving environmental risk at least once during each of the past 3 school years." Thus, this measure combined the frequency and recency components of past behavior (Bagozzi \& Warshaw, 1990; Bagozzi et al., 1992; Bagozzi \& Kimmel, 1995).

As indicated by this list, the constructs in this study were measured with a single or two items. The use of single or few items to assess the three theories constructs is standard practice [e.g. a recent meta analysis found 52 tests of the TPB that used a single item to measure subjective norm as opposed to 32 tests that used a multiple item scale (Armitage \& Conner, 2001) and no study with science teachers appears to have used more than one direct measure of subjective norm], based in part on authors' reports that this is a reliable and valid way to measure their theories' constructs (Ajzen \& Fishbein, 1980; Ajzen \& Madden, 1986; Bagozzi \& Kimmel, 1995).

\section{Sampling and Response Rate}

The individuals who responded to the items described here consisted of a stratified random sample of Grade 6-12 science teachers obtained from the Michigan, Ohio, and Wisconsin Departments of Education. Of the 2832 Grade 6-12 science teachers who received the questionnaire through bulk mail, 1336 returned it $\left(r_{\text {unadjusted }}=47 \%\right)$. A nonresponse survey showed that many of the selected teachers in the sample no longer taught Grade 6-12 science $(39 \%)$ and that a few questionnaires were nondeliverable $(0.09 \%)$. As suggested by Dillman (2000), the mail survey's response rate was therefore adjusted to $80 \%$.

\section{Subjects}

Completed mail questionnaires were returned by Michigan $(n=430)$, Ohio $(n=455)$, and Wisconsin $(n=449)$ science teachers. ${ }^{1}$ Grades $6-12$ and all science subjects were represented in the sample. The mean number of years respondents taught science was $\bar{x}=16$ [standard deviation $(\mathrm{SD})=10]$. Many respondents completed coursework beyond their masters degree $(45 \%$; $n=601)$. The majority of respondents were male $(69 \% ; n=922)$.

\section{Analysis}

For the study reported here, only data from subjects who responded to all 14 items were used for analyses. Confirmatory factor analysis (CFA) was conducted using LISREL Version 8.0 to examine composite reliabilities as well as convergent and discriminant validity when constructs were measured with more than one item (Bollen, 1989; Bagozzi \& Kimmel, 1995). All three theories were tested using SPSS Version 9.0 standard and sequential multiple regression, ${ }^{2}$ which was also used to obtain squared semipartial correlations $\left(s r_{\mathrm{i}}^{2}\right)$ (Tabachnick \& Fidell, 1996). Squared semipartial correlations were examined because the theories' determinants were significantly, and in some instances highly correlated. When product terms were included in the multiple regression analysis, all variables were mean centered before analysis.

It was not possible to conduct a meta-analysis of results published by previous studies conducted with teachers (Table 2) because data needed for such an analysis have generally not been reported (Hedges \& Olkin, 1985). 
Results

\section{Reliability and Validity}

The four attitude (i.e., $A_{a c t}, A_{s}, A_{f}, A_{p}$ ) constructs were measured with two items each, and therefore the reliability and validity of these eight measures were examined using confirmatory factor analysis.

The $\chi^{2}$ for the four-factor model was large relative to the degrees of freedom [i.e., $\chi^{2} / \mathrm{df}>2$ (Bryne, 1989)] with $\chi^{2}(\mathrm{df}=14, n=1240)=181.92, p<.01$. However, the model was concluded to fit because the $\chi^{2}$ was probably affected by the study's large sample size (Bentler, 1980; Loehlin, 1987; Jöreskog \& Sörbom, 1989). Moreover, model fit was supported by other fit index results. The root mean square residual (RMR) was only slightly larger than .019 (Fassinger, 1987) at .028, the root mean square error of approximation (RMSEA) was .10 (Browne \& Cudeck, 1993), the nonnormed fit index (NNFI) or Tucker-Lewis index was $>.90$ (Tucker \& Lewis, 1973) at .95, and the goodness of fit index (GFI) and comparative fit index (CFI) were also >.90 (Bentler, 1992) at .97 and .98 , respectively.

Under the assumption of model fit, composite reliabilities were calculated next. Composite reliabilities are calculated similar to Cronbach alpha except that measures are weighted by their factor loadings instead of receiving equal weights (Bagozzi \& Kimmel, 1995). The factor loadings for the measures and the composite reliabilities were high for three of the four factors (i.e., $\mathrm{A}_{\text {act }}=.93, \mathrm{~A}_{\mathrm{s}}=.95$ and $\left.\mathrm{A}_{\mathrm{f}}=.94\right)$. The fourth factors' low reliability $\left(\mathrm{A}_{\mathrm{p}}=.45\right)$ suggested that the two intended items did not measure the same construct and the measure with the lower factor loading was dropped. Eliminating this measure resulted in an improved fit of the four-factor attitude model, mainly with a large reduction in the RMR to .009.

Construct validity was assessed by examining convergent and discriminant validity. Convergent validity is supported when measures of the hypothesized factors load high on the proper factors, suggesting that the measures of each factor share significant amounts of common variance (Bagozzi \& Kimmel, 1995). In this study, convergent validity for $A_{a c t}, A_{s}$, and $A_{f}$ was supported by these six measures' high factor loadings (ranging from .90 to .99) as well as the improved fit index results for the model excluding the $\mathrm{A}_{\mathrm{p}}$ item with the lower factor loading.

Because of the satisfactory model fit results, it was also appropriate to explore the extent of discriminant validity among the four factors, i.e., the extent to which the factors were distinct and could be differentiated (Bagozzi \& Kimmel, 1995). Discriminant validity can be assessed by examining the factor correlations corrected for attenuation due to the unreliabilities in the measures (Bagozzi \& Kimmel, 1995). The attitude constructs' discriminant validity was supported in this study as correlations in the four factor matrix were low to moderate (here, .09-.67) and significantly less than 1.00 [i.e., $<1$ by an amount twice their respective standard errors (here, $.02-.03)]$.

Based on these reliability and validity results, the TRA and TPB were analyzed with both measures for $A_{a c t}$ and the TT was analyzed with both measures for $A_{s}$ and $A_{f}$ but only with a single measure for $A_{p}$.

\section{TRA and TPB}

Eight models were examined, i.e., the TRA and TPB, the TRA, and TPB augmented with past behavior, and these four models including select interactions. Select interactions were examined for comparison purposes because some previous science education investigators included them in their analyses. 
Standard multiple regression results indicated that the eight models' multiple correlations $(R)$ were all significantly different from zero and ranged from .48-.62 (Table 3 ). In addition, all hypothesized TRA (attitude toward the behavior, subjective norm) and TPB (attitude toward the behavior, subjective norm, perceived behavioral control) determinants contributed significantly to predicting science teachers' intention to incorporate environmental risk education (Table 3). As hypothesized, the TPB better predicted science teachers environmental risk education intentions than the TRA with a 5\% increase in explained variance $(F \Delta(1,1266)=75.89, p<.001)$.

The four examined interactions can be concluded not to have improved the prediction of science teachers' environmental risk education intentions. $\mathrm{A}_{\text {act }} \mathrm{SN}$ was the only interaction that contributed significantly to predicting science teachers' intention to incorporate environmental risk education, and this interaction did so in 3 of the 4 models. However, this interaction only increased the explained variance $\left(R^{2}\right)$ in 1 of the 4 models (i.e., the TRA) and in that instance, only by $1 \%(F \Delta(1,1249)=7.37, p=.007)$. Moreover, when past behavior was added to the model, $\mathrm{A}_{\text {act }} \mathrm{SN}$ no longer improved the models' prediction of intention to act.

Past behavior contributed significantly to predicting science teachers' environmental risk education intentions (Table 3). Past behavior improved the prediction of intention to act by $14 \%$ $(F \Delta(1,1263)=274.34, p<.001)$ when added to the TRA and by $10 \%$ when added to the TPB $(F \Delta(1,1262)=202.69, p<.001)$. When attitude toward the behavior and subjective norm were controlled for, the relation between past behavior and intention to act significantly decreased from $\beta=.55(p<.001)$ to $\beta=.41(p<.001)$. When attitude toward the behavior, subjective norm, and perceived behavioral control were controlled for, the relation between past behavior and intention to act further significantly decreased to $\beta=.38(p<.001)$.

Altogether, between $23 \%$ and $38 \%$ (also $23 \%$ and $38 \%$ adjusted) of the variability $\left(R^{2}\right)$ in science teachers' intention to incorporate environmental risk education was explained by the determinants in the models (Table 3). The unique contributions $\left(s r_{\mathrm{i}}^{2}\right)$ of the significant independent variables (excluding the significant interaction) summed between .14 and .26, and thus these independent variables in combination contributed between .06 and .24 in additional shared variability.

The TPB augmented with past behavior can be concluded to be the best of the eight examined TRA and TPB models in terms of predicting science teachers' intentions to incorporate environmental risk education. This is because the TPB augmented with past behavior explained the greatest amount of variance that did not increase with the inclusion of interactions. In addition, past behavior was the most important predictor of intention to act, followed by attitude toward the behavior, perceived behavioral control, and subjective norm. This conclusion is based on a comparison of the magnitudes of the standardized regression coefficients $(\beta)$ and squared semipartial correlations $\left(s r_{\mathrm{i}}^{2}\right)$ of the determinants.

\section{Theory of Trying}

Standard multiple regression results for the TT indicated that the multiple correlation $(R=.61)$ differed significantly from zero (Table 4$)$. In addition, 5 of the TT's 9 hypothesized determinants contributed significantly to predicting science teachers' intention to incorporate environmental risk education. These 5 significant TT determinants were attitude toward success, expectation of success, attitude toward the process, subjective norm, and past behavior. Although the remaining 4 TT's independent variables were significantly correlated with intention to act, these relations were mediated or made redundant by the relations among the 5 significant determinants and intention to act. 


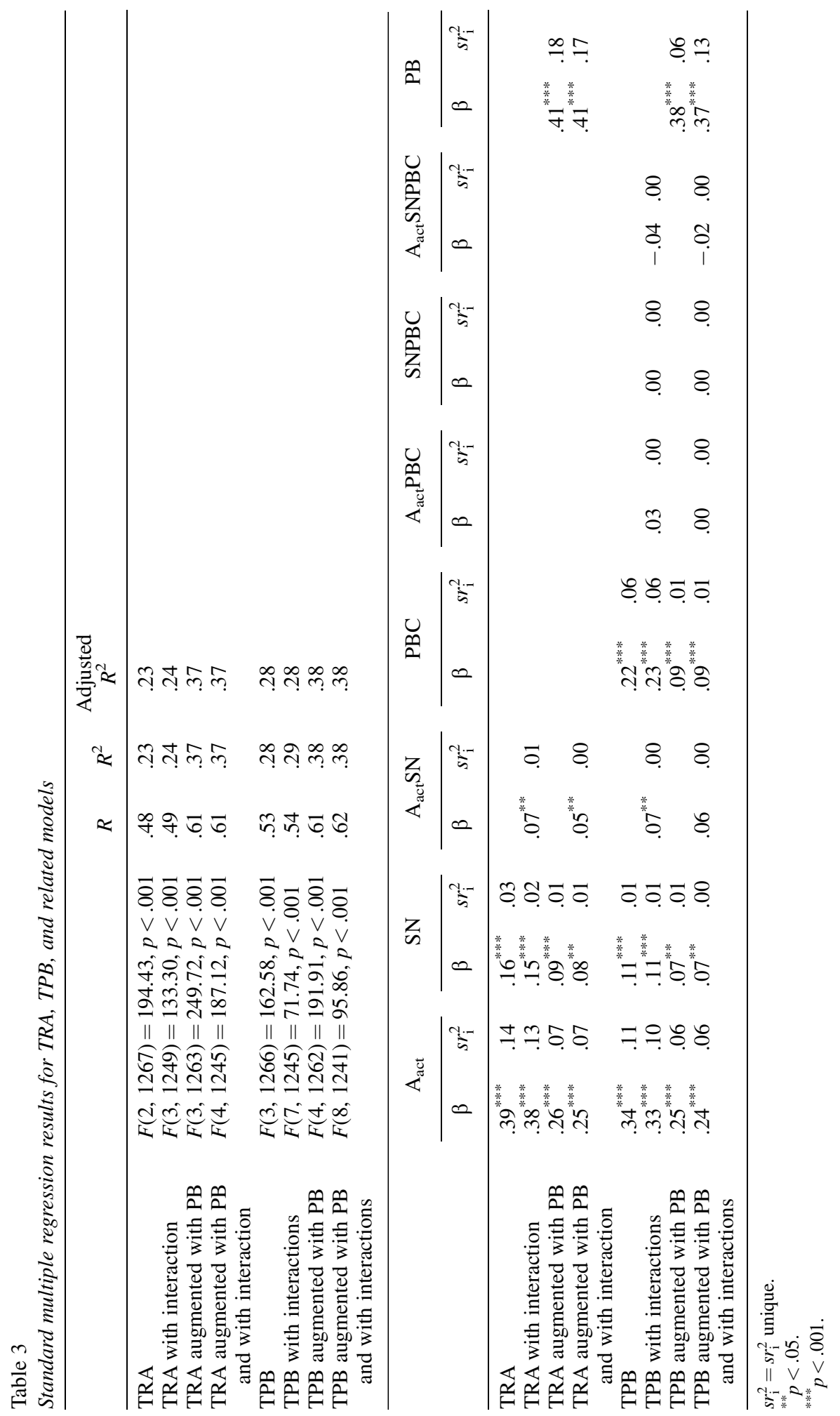




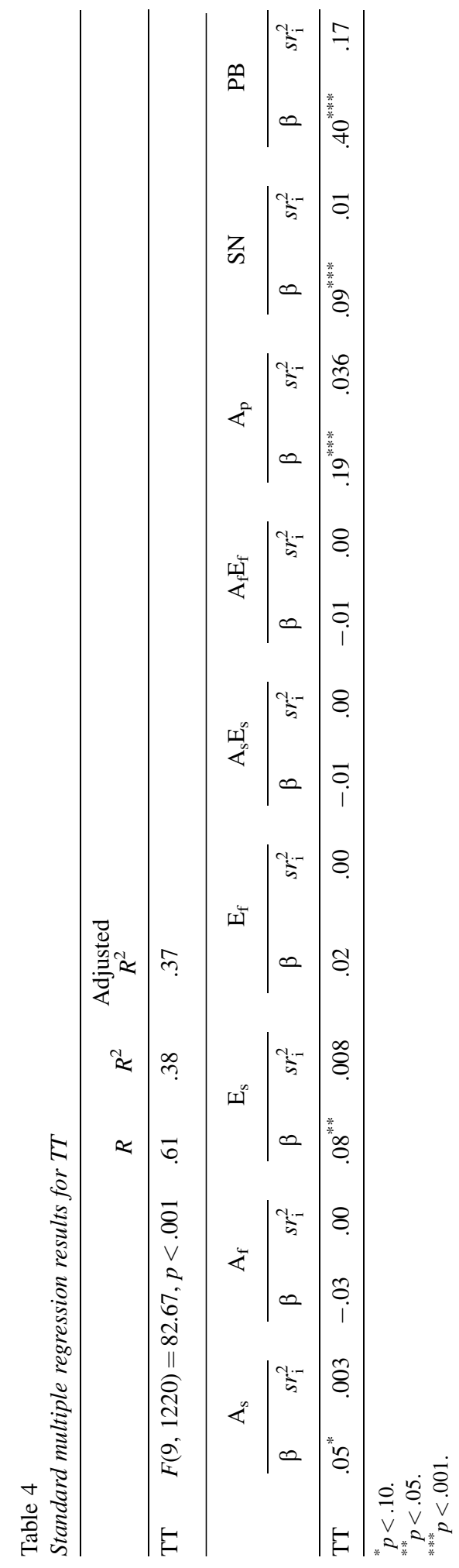


Altogether, $38 \%$ (37\% adjusted) of the variability $\left(R^{2}\right)$ in science teachers' intention to incorporate environmental risk education was explained by attitude toward success, expectation of success, attitude toward the process, subjective norm, and past behavior. The unique contributions $\left(s r_{\mathrm{i}}^{2}\right)$ of each of these five independent variables summed to .23 , indicating that the five independent variables in combination contributed an additional .14 in shared variability.

Past behavior was the most important predictor of intention to act, followed by attitude toward the process, subjective norm, expectation of success, and attitude toward success. This conclusion is based on a comparison of the magnitudes standardized regression coefficients $(\beta)$ and squared semipartial correlations $\left(s r_{\mathrm{i}}^{2}\right)$ of the five determinants.

In terms of ability to predict science teachers' intention to incorporate environmental risk education, the TT (adjusted $\left.R^{2}=.37\right)$ performed better than the TPB $\left(R^{2}=.28\right)$ but similarly to the TPB augmented with past behavior (adjusted $R^{2}=.38$ ). In addition, only 5 of the 9 hypothesized determinants of the TT were significant predictors of science teachers' intention to incorporate environmental risk education, whereas all 4 of the hypothesized determinants of the TPB augmented with past behavior were significant predictors.

\section{Discussion}

The results of the study reported here are remarkably consistent with findings reported by prior studies including those conducted with science teachers. For example, across studies the TRA, TPB, and to some extent TT are able to explain about the same amounts of variance in intention to act. Moreover, the magnitudes and relative strengths of the theories' determinants of intention to act are similar and do not seem to vary much with the type of behavior or situation, or based on individual differences.

With regard to the TRA, the study's multiple correlation $(R=.48)$ was only somewhat lower than the mean multiple correlation across studies conducted with teachers $(\bar{x} R=.54$, range .10-.85) and in the range of studies conducted with other populations $(\bar{x} R=.71$, range $.23-.94)$. Attitude toward the behavior $(\beta=.39)$ better predicted intention to act than subjective norm $(\beta=.16)$, which is consistent with findings from a meta-analysis of 150 TRA studies that found that attitude toward the behavior is generally a better predictor of intention to act than subjective norm [Van den Putte, 1991 (as cited by Eagly \& Chaiken, 1993)]. Moreover, the magnitude of the two determinants is similar to those reported by other studies conducted with teachers (attitude toward the behavior $\bar{x} \beta=.47$, range .12-.69; subjective norm $\bar{x} \beta=.18$, range $-.39-.46)$.

With regard to the TPB, the study's multiple correlation $(R=.53)$ was close to the mean multiple correlation across studies conducted with teachers $(\bar{x} R=.56$, range $.26-.80)$ (Table 2$)$ and in the range of studies conducted with other populations $[\bar{x} R=.70$, range $.43-.94$ (Ajzen, 1991); $\bar{x} R=.63$ (Armitage \& Conner, 2001)]. Attitude toward the behavior was the most important predictor of intention to act $(\beta=.34)$ and its magnitude was similar to that reported by other studies conducted with teachers $(\bar{x} \beta=.38$, range $.20-.57)$ and with other populations $(\bar{x} \beta=.39$, range $.10-.79)$. Perceived behavioral control was the next most important predictor of intention to act $(\beta=.22)$ and its magnitude was also similar to that found by other studies conducted with teachers $(\bar{x} \beta=.24$, range $-.31-.54)$ and somewhat lower than that found by studies conducted with other populations $(\bar{x} \beta=.39$, range $.07-.84)$. Subjective norm was the least most important predictor of intention to act $(\beta=.11)$ and its magnitude was lower than that found by other studies conducted with teachers $(\bar{x} \beta=.25$, range $-.18-.30)$ but similar to that found by studies conducted with other populations $(\bar{x} \beta=.17$, range $-.24-.35)$. The finding that attitude toward the behavior is generally the best predictor of the TPB, followed by perceived behavioral 
control; finally, subjective norm is also consistent with results from a meta-analysis of 185 tests of TPB (Armitage \& Conner, 2001).

As hypothesized, the TPB through its inclusion of perceived behavioral control was better able to predict science teachers' environmental risk education intentions than the TRA with a significant $5 \%$ increase in explained variance. Prior studies that compared the TRA and TPB found similar differences. For example, the same 5\% difference in the explained variance of intention to act by the TPB over the TRA was identified based on a meta-analysis of 185 tests (Armitage \& Conner, 2001).

With regard to the TT, this study's multiple correlation $(R=.61)$ was close to that of studies conducted with other populations $(\bar{x} R=.68$, range .33-.78) (Bagozzi \& Warshaw, 1990; Bagozzi et al., 1992; Bagozzi \& Kimmel, 1995). Subjective norm significantly predicted intention to act in this study's TT $(\beta=.09)$ but not as strongly as in past TT studies $(\bar{x} \beta=.32$, range $.20-.50)$ (Bagozzi \& Warshaw, 1990; Bagozzi \& Kimmel, 1995). Consistent with overall findings from past TT studies (Bagozzi \& Warshaw, 1990; Bagozzi et al., 1992; Bagozzi \& Kimmel, 1995), attitude toward success, expectation of success, and attitude toward the process significantly predicted intention to act. Inconsistent with findings from some past TT studies, the interaction between attitude toward success and expectation of success, attitude toward failure and expectation of failure, as well as their interaction did not significantly predict intention to act. Moreover, the magnitude of attitude toward the process was similar in size to that reported by these prior studies but the magnitudes of attitude toward success and expectation of success were much smaller. Finally, past behavior was strongly related to intention to act in this study's TT $(\beta=.40)$ and this finding is similar to results found by past TT studies $(\bar{x} \beta=.38$, range $.22-.49$ ) (Bagozzi \& Warshaw, 1990; Bagozzi \& Kimmel, 1995).

Unlike the only other study that compared the TRA and TPB, the TRA and TPB augmented with past behavior, and the TT (Bagozzi \& Kimmel, 1995), and as hypothesized, the TT better predicted intention to act (adjusted $R^{2}=.37$ ) than the TPB (adjusted $R^{2}=.28$ ) in this study. Similar to the other study that compared these three theories and related models (Bagozzi \& Kimmel, 1995), however, when the TRA and TPB were augmented with past behavior they performed the same (TRA and TT adjusted $R^{2}=.37$ ) and almost the same as the TT in terms of prediction (TPB adjusted $R^{2}=.38$ ).

When past behavior was used to augment the TRA and TPB in this study, the explained variance in intention to act increased by $14 \%$ for the TRA and $10 \%$ for the TPB. These increases in explained variance in intention to act as a result of past behavior were also similar to those found by prior studies. Research conducted with other populations on three behaviors indicated a mean $8 \%$ (range 6-11\%) increase in the explained variance in intention to act when past behavior was added to the TRA (Bagozzi \& Kimmel, 1995; Albarracin, Fishbein, \& Middlestadt, 1998). Research conducted with other populations on five behaviors indicated a mean 19\% (range 3$54 \%$ ) increase in the explained variance in intention to act when past behavior was added to the TPB (Rise, 1992; Bagozzi \& Kimmel, 1995; Reinecke, Schmidt, \& Ajzen, 1996; Albarracin et al., 1998). A recent review of the role of past behavior in predicting intention to act and future behavior also found that past behavior was a significant predictor of intention to act after controlling for the TRA determinants with an effect size of .25 and after controlling for TPB determinants with an effects size of .28 (Ouellette \& Wood, 1998).

Based on this discussion, it can be concluded that of the models examined here, the TPB augmented with past behavior and the TT are best able to predict science teachers' intention to act, when the target behavior is not completely under their volitional control. Specifically, given the consistency of results across studies, these two theories are likely to explain an average of about $40 \%$ of the variance in science teachers' intention to act, which is high for field-based 
investigations (Bagozzi, personal communication; Sutton, 1998). One advantage of the TPB is that it accomplishes this level of prediction with a smaller number of determinants than the TT (Sutton, 1998), and one advantage of the TT is that it offers a potentially more refined explanatory mechanism underlying intention formation in the context of goal pursuit (Bagozzi \& Warshaw, 1990).

Given that the TPB and TT success in prediction has been established, they can be concluded to be useful in explaining what leads science teacher to form intentions to act (Sutton, 1998), suggesting that the theories should be used to guide the design, implementation, and subsequent evaluation of behavioral interventions such as professional development programs. The remaining discussion therefore focuses on implications for interventions and identifies relevant issues for future research.

\section{Attitudes and Expectations}

Of the three determinants in the TPB, the research described here suggests that attitude toward the behavior is likely to be the strongest predictor of science teachers' intention to act. Based on the $\mathrm{TPB}$, this suggests that interventions should focus on assessing and seeking to improve science teachers' overall evaluation of the target behavior by increasing their perception of the likelihood that performance of the behavior will lead to particular outcomes and creating more favorable evaluations of those outcomes.

Findings from tests of the TT conducted so far also support that interventions should focus on other science teacher attitudes and related constructs to promote their intention to act: specifically, attitude toward the process, attitude toward success, and expectation of success. Based on the TT, this means interventions should seek to enhance science teachers' beliefs associated with the experiences that they will have as they pursue the target behavior (maximizing beliefs regarding pleasurable ones and minimizing beliefs regarding undesirable ones), the values or gains of succeeding in engaging in the target behavior, and the likelihood of such success occurring. To enhance science teachers' assessment of the latter, it is necessary to increase their perceived ability to carry out the behavior (i.e., personal self-efficacy) as well as to address their perceptions of the likely influence of causal factors beyond their control (Carver \& Scheier, 1998).

There has not been a large enough number of tests of the TT to determine to what extent science teachers' attitudes toward failure and expectations of failure influence their intention to act. The study conducted here did not find that these determinants had an influence; however, future studies and especially interventions should test this because such negative attitudes and expectations could explain why some teachers are resistant to behavior change in certain contexts. Future research should use multiple items to assess these TT constructs because the limited number of measures may explain why the observed relations with intention to act were not stronger or significant predictors.

\section{Perceived Behavioral Control}

Overall results suggest that perceived behavioral control is an important determinant of science teachers' intention to act; i.e., science teachers form intentions they are confident they can enact or over which they perceive they have self-efficacy. To increase science teachers' perceived behavioral control, the TPB suggests that professional development interventions should increase their beliefs that they have access to necessary resources and opportunities to enact the target behavior and the power of these factors to facilitate the behavior. Such interventions should address both internal (e.g., knowledge, skills) and external control (e.g., barriers, role of others) factors. 
It should be noted that whereas Ajzen (1991) argued that PBC and self-efficacy are interchangeable, there has been debate that this may not be the case (e.g., Bandura, 1986, 1992). Indeed, a meta-analysis of TPB tests found that for the prediction of intention to act, self-efficacy explained an additional 7\%, whereas PBC explained an additional 5\% of variance (Armitage \& Conner, 2001). Thus, future researchers should consider including measures that more fully capture this aspect of influence on science teachers' behaviors.

\section{Subjective Norm}

Compared with the other determinants in the TPB, overall results suggest that under most circumstances, subjective norm is likely to be the weakest predictor of science teachers' intention to act. Nonetheless, on average, subjective norm significantly predicts teachers' intention to act and in some cases is a stronger predictor of intention to act for this, versus other populations, and thus should be targeted by professional development interventions. According to the TPB, such interventions should show that administrators, peers, students, parents, and other individuals that science teachers perceive as important are supportive of the target behavior and how they would benefit from complying or working with these referents.

When past science education investigators have not found subjective norm to be a significant or strong predictor of intention to act, they have argued that normative factors are not an important influence on science teachers' behaviors. Given the findings of this review and that subjective norm has only been measured with a single item rather than multiple, possibly more reliable ones, however, it may be a stronger determinant of intention to act than suggested by past results (Armitage \& Conner, 2001). In fact, current approaches to measuring subjective norm have been concluded as likely to fail to capture the many aspects of social influence (Conner \& Armitage, 1998).

\section{Past Behavior}

Consistent with research that has identified past behavior as a strong predictor of future behavior (Ouellette \& Wood, 2001), this study found that past behavior was not only a significant predictor but was the strongest one of intention to act when added to the TRA and TPA or as part of the TT. As mentioned in the introduction, this finding can be interpreted in a theoretical or methodologic way. In the context of the study reported here, science teachers' intention to incorporate environmental risk education may be interpreted as largely driven by habit. Alternatively, it may be concluded that the TPB is incomplete and does not include all possible determinants of science teachers' intention to incorporate environmental risk education. Because incorporating environmental risk education is a behavior that science teachers are unlikely to engage in on a daily or weekly basis but rather at select times of the year (Ouellette \& Wood, 2001), their environmental risk education intentions are unlikely to be habitual. Instead, there are likely to be determinants in addition to those included in the theories that drive their environmental risk education intentions.

Other researchers similarly argue that the TPB is incomplete and have suggested exploring the addition of affective considerations, moral obligations, self-identity, and others (Bagozzi, 1992; Conner \& Armitage, 1998; Eagly \& Chaiken, 1993). Future research should therefore consider testing such additional determinants for their ability to improve further on the prediction and explanation of science teachers' intention to act and subsequent behavior.

It is important that such future studies include past behavior as a determinant of intention to act and future behavior. This recommendation is made not just to test the sufficiency of the theories 
under investigation, but because in many instances science teachers' habits are more likely to drive their behaviors (e.g., their use of specific instructional methods) than deliberative considerations as reflected by the theories examined here. If specific science teacher behaviors are determined to be habitual, interventions will need to be designed not just to facilitate new behaviors but to impede existing behaviors. Future research involving such interventions will be useful in that it can provide insight into how to bring science teachers' habitual behaviors under the influence of controlled processes [e.g., by helping teachers formulate plans to initiate and implement new behaviors, providing opportunities for repetition of new behaviors, eliminating support for habitual behaviors and creating supporting environments for new behaviors, highlighting shortand long-term positive consequences of new behaviors (Ouellette \& Wood, 2001)]. Moreover, helpful insights may be obtained from learning to what extent interventions targeting attitude toward the behavior, perceived behavioral control, and subjective norm influence science teachers who have and have not formed habitual behaviors (Sheeran \& Taylor, 1999). Finally, as with the determinants discussed so far, it is important that future investigations use multiple reliable measures of past behavior as these tend to reveal stronger effects (Ouellette \& Wood, 2001).

In conclusion, I do not believe that future research is needed on the immediate determinants of intention to act as specified by the TRA and TPB with science teachers. Results across the studies reviewed and reported here support the ability of these theories to predict and explain science teachers' intention to act, and thus their usefulness in designing, implementing, and evaluating professional development interventions that seek to change science teachers' behaviors. There is, however, a need to identify determinants that, if added to the TPB, can further improve our understanding of science teachers' behaviors not under their volitional control. These investigations should also further explore the importance of attitudes toward the process, success, and failure as well as expectations of success and failure to science teachers' intention formation. In addition, any research on attitude-behavior theories would in general benefit from using a greater number of more reliable measures. Both the reliability and validity of these measures can be examined using the process illustrated in the Results section of this article based on Bagozzi and Kimmel (1995). Finally, this article did not focus on reviewing and examining the relation between underlying beliefs and the theories' immediate determinants of intention to act or on the relation between intention to act and behavior (partly because few studies with teachers have investigated the latter). Such work may be helpful, although, based on the findings of this review, results are likely to be similar to those of studies conducted with other populations.

The author thanks Dr. Richard Bagozzi for his assistance with various aspects of this study. This research was supported in part by funding from the Michigan Sea Grant College Program, Project R/EP-7, under Grant 1N89AA-D-SG083 from the Office of Sea Grant, National Oceanic and Atmospheric Administration (NOAA), U.S. Department of Commerce, and funds from the State of Michigan. The U.S Government is authorized to produce and distribute reprints for governmental purposes notwithstanding any copyright notation appearing herein.

\section{Notes}

${ }^{1}$ Two of the 1336 returned questionnaires could not be assigned to a state because these respondents removed their identification codes.

${ }^{2}$ In addition to multiple regression, structural structural equation modeling (SEM) (Jöreskog \& Sörbom, 1993) was used to examine the TRA and TPB models that did not include product terms. Results from the SEM analysis were consistent with those of the multiple regression analysis and indicated that of the four examined TRA and TPB models, the TPB augmented with past behavior had the best model fit. Detailed SEM results are available from the author. 


\section{References}

American Association for the Advancement of Science. (1993). Project 2061: Benchmarks for science literacy. New York: Oxford University Press.

Ajzen, I. (1985). From intentions to actions: A theory of planned behavior. In Kuhl, J. \& Beckmann, J. (Eds.), Action control: From cognition to behavior. New York: Springer-Verlag.

Ajzen, I. (1988). Attitudes, personality, and behavior. Chicago: Dorsey.

Ajzen, I. (1991). The theory of planned behavior: Some unresolved issues. Organizational Behavior and Human Decision Processes, 50, 179-211.

Ajzen, I. (1996). The directive influence of attitudes on behavior. In Gollwitzer, P.M. \& Bargh, J.A. (Eds.), The psychology of action: Linking cognition and motivation to behavior. New York: Guildford Press.

Ajzen, I. \& Fishbein, M. (1973). Attitudinal and normative variables as predictors of specific behaviors. Journal of Personality and Social Psychology, 27, 41-57.

Ajzen, I. \& Fishbein, M. (1977). Attitude-behavior relations: A theoretical analysis and review of empirical research. Psychological Bulletin, 84, 888-918.

Ajzen, I. \& Fishbein, M. (1980). Understanding attitudes and predicting social behavior. Englewood Cliffs, NJ: Prentice-Hall.

Ajzen, I. \& Madden, T.J. (1986). Prediction of goal-directed behavior: Attitudes, intentions, and perceived behavioral control. Journal of Experimental Social Psychology, 22, 453-474.

Albarracin, D., Fishbein, M., \& Middlestadt, S. (1998). Generalizing behavioral findings across times, samples and measures: A study of condom use. Journal of Applied Social Psychology, 28, 657-674.

Armitage, C.J. \& Conner, M. (2001). Efficacy of the theory of planned behavior: a metaanalytic review. British Journal of Social Psychology, 40, 471-499.

Bagozzi, R.P. (1992). The self-regulation of attitudes, intentions and behavior. Social Psychology Quarterly, 55, 178-204.

Bagozzi, R.P., Davis, F.D., \& Warshaw, P.R. (1992). Development and test of a theory of technological learning and usage. Human Relations, 45, 659-686.

Bagozzi, R.P. \& Kimmel, S.K. (1995). A comparison of leading theories for the prediction of goal-directed behaviors. British Journal of Social Psychology, 34, 437-461.

Bagozzi, R.P. \& Warshaw, P.R. (1990). Trying to consume. Journal of Consumer Research, 17, 127-140.

Bandura, A. (1977). Self-efficacy: Toward a unifying theory of behavioral change. Psychology Review, 84, 191-215.

Bandura, A. (1982). Self-efficacy mechanism in human agency. American Psychologist, 37, $122-147$.

Bentler, P.M. (1980). Multivariate analysis with latent variables: Causal modeling. Annual Review of Psychology, 31, 419-456.

Bentler, P.M. (1992). On the fit of models to covariances and methodology to the bulletin. Psychological Bulletin, 112, 400-404.

Bentler, P.M. \& Speckart, G. (1979). Models of attitude-behavior relations. Psychological Review, 86, 452-464.

Bollen, K.A. (1989). Structural equations with latent variables. New York: Wiley.

Briscoe, G.J. (1992). Need for risk standards and education. Risk Analysis, 12, 331.

Brown, M.W. \& Cudeck, R. (1993). Alternative ways of assessing model fit. In Bollen, K.A. \& Long, J.S. (Eds.), Testing structural equation models. Newbury Park, CA: Sage. 
Burak, L.J. (1992). The examination and prediction of elementary school teachers' intentions to teach HIV/AIDS education. Unpublished dissertation, University of Oregon, Eugene.

Burak, L.J. (1994). Examination and prediction of elementary school teachers' intentions to teach HIV/AIDS education. AIDS Education and Prevention, 6, 310-321.

Bybee, R.W. \& Ben-Zvi, N. (1998). Science curriculum: transforming goals to practices. In Fraser, B.J. \& Tobin, K.G. (Eds.), International handbook of science education (pp. 487-498). Boston, MA: Kluwer Academic.

Byrne, B.M. (1989). A primer of LISREL: Basic applications and programming for confirmatory factor analytic models. New York: Springer-Verlag.

Carver, C.S. \& Scheier, C.S. (1998). On the self-regulation of behavior. Cambridge, UK: Cambridge University Press.

Chen, C.S. (1988). Cognitive style and intention change: The effects of anecdotal and datasummary persuasive strategies on teachers' intentions to teach about the environment. Unpublished dissertation, University of Texas, Austin.

College Board. (2000). Advanced placement program environmental science course. Retrieved July 19, 2000, from the World Wide Web: http://www.collegeboard.com/ap/ environmental-science/html/cours001.html.

Conner, M. \& Armitage, C.J. (1998). Extending the theory of planned behavior: a review and avenues for further research. Journal of Applied Social Psychology, 28, 1429-1464.

Crawley, F.E. (1988). Determinants of physical science teachers' intentions to use investigative teaching methods: A test of the theory of reasoned action. (ERIC Document Reproduction Service No. ED 292 675)

Crawley, F.E. (1990). Intentions of science teachers to use investigative teaching methods: A test of the theory of planned behavior. Journal of Research in Science Teaching, 27, 685-697.

Desouza, J.M.S. (1993). A study of science teachers' attitudes and intentions to engage in collaborative reflective practice. Unpublished dissertation, University of Ohio, Toledo.

Dillman, D.A. (2000). Mail and Internet surveys: The tailored design method. New York: Wiley.

Eagly, A.H. \& Chaiken, S. (1993). The psychology of attitudes. New York: Harcourt, Brace, Jovanovich.

Fassinger, R.E. (1987). Use of structural equation modeling in counseling psychology research. Journal of Counseling Psychology, 34, 425-436.

Fishbein, M. (1980). A theory of reasoned action: Some applications and implications. In Howe, H. \& Page, M. (Eds.), Nebraska symposium on motivation (pp. 65-116). Lincoln: University of Nebraska Press.

Fishbein, M. \& Ajzen, I. (1975). Belief, attitude, intention, and behavior: An introduction to theory and research. Reading, MA: Addison-Wesley.

Gorman Smith, B. (1993). Teacher intentions to use and their actual use of microcomputer science laboratory interface materials in science instruction: An application of the theory of planned behavior. Unpublished dissertation, Pennsylvania State University, College Station.

Gregory, R. (1991). Critical thinking for environmental health risk education. Health Education Quarterly, 18, 273-284.

Haney, J.J. (1994). The determinants of Ohio science teachers' intentions to implement the four strands of the state science model into their classroom instruction. Unpublished dissertation, University of Ohio, Toledo.

Haney, J.J. \& Lumpe, A.T. (1995). A teacher professional development framework guided by reform policies, teachers' needs, and research. Journal of Science Teacher Education, 6, 187196. 
Haney, J.J, Czerniak, C.M., \& Lumpe, A.T. (1996). Teacher beliefs and intentions regarding the implementation of science education reform strands. Journal of Research in Science Teaching, 33, 971-993.

Hedges, L.V. \& Olkin, I. (1985). Statistical methods for meta-analysis. San Diege, CA: Academic Press.

Independent Commission on Environmental Education. (1997). Are we building environmental literacy? Washington, DC: Author.

Jesus, S.N. \& Abreu, M.V. (1994). Study of teachers' motivation to motivate students by the theory of planned behavior. (ERIC Document Reproduction Service No. ED 400 235)

Jöreskog, K.G. \& Sörbom, D. (1989). LISREL 7.0: A guide to program and applications (2nd ed.) Chicago: SPSS.

Jöreskog, K.G. \& Sörbom, D. (1993). LISREL 8.0. Chicago: Scientific Software International.

Kaplan, S. (1997). The words of risk analysis. Risk Analysis, 17, 407-417.

Koballa, T.R. (1986). Teaching hands-on science activities: Variables that moderate attitudebehavior consistency. Journal of Research in Science Teaching, 23, 493-502.

Koballa, T.R. (1989). Using salient beliefs in designing a persuasive message about teaching energy conservation practices to children. Science Education, 73, 547-567.

Lewin, K., Dembo, T., Festinger, L., \& Sears, P.S. (1944). Level of aspiration. In Hunt, J.M. (Ed.), Personality and the behavior disorder (pp. 333-378). New York: Ronald Press.

Loehlin, J.C. (1987). Latent variable models: An introduction to factor, path and structural analysis. Hillsdale, NJ: Erlbaum.

Lumpe, A.T., Haney, J.J., \& Czerniak, C.M. (1998a). Science teacher beliefs and intentions regarding the use of cooperative learning. School Science and Mathematics, 98, 123-135.

Lumpe, A.T., Haney, J.J., \& Czerniak, C.M. (1998b). Science teacher beliefs and intentions to implement science-technology-society (STS) in the classroom. Journal of Science Teacher Education, 9, 1-24.

Lumpe, A.T., Haney, J.J., \& Czerniak, C.M. (2000). Assessing teachers beliefs about their science teaching context. Journal of Research in Science Teaching, 37, 275-292.

Madden, T.J., Scholder, E.P., \& Ajzen, I. (1992). A comparison of the theory of planned behavior and the theory of reasoned action. Personality and Social Psychology Bulletin, 18, 3-9.

Middlestadt, S.E., Ledsky, R., \& Sanchack, J. (1999). Elementary school teachers' beliefs about teaching environmental education. Rock Spring, GA: North American Association for Environmental Education.

National Research Council. (1996). National science education standards. Washington, DC: National Academy Press.

Ouellette, J.A. \& Wood, W. (1998). Habit and intention in everyday life: The multiple processes by which past behavior predicts future behavior. Psychological Bulletin, 124, 54-74.

Reinecke, J., Schmidt, P., \& Ajzen, I. (1996). Application of the theory of planned behavior to adolescents' condom use: A panel study. Journal of Applied Social Psychology, 26, 749-772.

Richardson, V. \& Placier, P. (2001). Teacher change. In Richardson, V. (Ed.), Handbook of research on teaching (4th ed.) (pp. 905-947). Washington, DC: American Educational Research Association.

Riechard, D.E. (1993). Risk literacy: Is it the missing link in environmental education? Journal of Environmental Education, 25, 8-12.

Rise, J. (1992). An empirical study of the decision to use condoms among Norwegian adolescents using the theory of reasoned action. Journal of Community and Applied Social Psychology, 2, 185-197. 
Sheeran, P. \& Taylor, S. (1999). Predicting intentions to use condoms: A meta-analysis and comparison of the theories of reasoned action and planned behavior. Journal of Applied Social Psychology, 28, 1624-1675.

Sheppard, B.H., Hartwick, J., \& Warshaw, P.R. (1988). The theory of reasoned action: A meta-analysis of past research with recommendations for modifications and future research. Journal of Consumer Research, 15, 325-343.

Sutton, S. (1998). Predicting and explaining intentions and behavior: How well are we doing? Journal of Applied Social Psychology, 28, 1317-1338.

Tabachnick, B.G. \& Fidell, L.S. (1996). Using multivariate statistics, third edition. New York: HarperCollins College.

Thousand, J.S. \& Burchard, S. (1990). Social integration: Special education teachers' attitudes and behaviors. American Journal on Mental Retardation, 94, 407-419.

Tobin, K. (1998). Issues and trends in the teaching of science. In Fraser, B.J. \& Tobin, K.G. (Eds.), International handbook of science education (pp. 129-152). Boston: Kluwer Academic.

Tobin, K., Tippins, D.J., \& Gallard, A.J. (1994). Research on instructional strategies for teaching science. In Gabel, D.L. (Ed.), Handbook of research on science teaching and learning (pp. 45-93). New York: Macmillan.

Triandis, H.C. (1977). Interpersonal behavior. Monterey, CA: Brooks/Cole.

Triandis, H.C. (1980). Values, attitudes, and interpersonal behavior. In Howe, H.E. Jr. \& Page, M.M. (Eds.), Nebraska Symposium on Motivation 1979 (pp. 195-259). Lincoln, NE: University of Nebraska Press.

Tucker, L.R. \& Lewis, C. (1973). A reliability coefficient for maximum likelihood factor analysis. Psychometrika, 38, 1-10.

Wilson, C. (1990). Education and risk. In Handmer, J. \& Penning-Roswell, E. (Eds.), Hazards and the communication of risk (pp. 53-68). Brookfield, VT: Gower.

Wishnick, Y.S. (1989). The underlying personal and social beliefs of regular elementary student teachers to teach students with mild learning handicaps. Unpublished dissertation, University of California, San Francisco.

Zint, M. (2001). Advancing environmental risk education. Risk Analysis, 21, 417-426.

Zint, M. \& Peyton, R.B. (2001). Improving risk education in grades 6-12: A needs assessment of Michigan, Ohio and Wisconsin science teachers. Journal of Environmental Education, 32, 46-54. 